\title{
COMPARATIVO DO CUSTO DE TRANSPORTE E DO FRETE RODOVIÁRIO DE AÇÚCAR PARA EXPORTAÇÃO, ORIGINADO DE POLOS PAULISTAS ${ }^{1}$
}

\author{
Carolina de Freitas Oliveira ${ }^{2}$ \\ Ciro Villela Oliva ${ }^{3}$ \\ Daniela Cristina Passoni ${ }^{4}$ \\ João Victor Crivellaro Loreti ${ }^{5}$ \\ Mariana Papa Stefanini ${ }^{6}$ \\ Rhuana Reijers ${ }^{7}$ \\ José Vicente Caixeta Filho ${ }^{8}$
}

Resumo: O Brasil é, nos dias de hoje, o maior produtor e exportador de açúcar do mundo, e seus principais concorrentes e formadores de preço são a Índia e a China. Na produção de tal commodity, destacam-se as usinas de açúcar e álcool do estado de São Paulo. O escoamento do produto ocorre, principalmente, pelo modal rodoviário, devido à maior agilidade e flexibilidade quando comparado com os demais modais, percorrendo as distâncias das usinas de produção até seu principal destino (e gargalo logístico), o Porto de Santos. Neste cenário, este trabalho objetivou avaliar o impacto dos custos de transporte (custos fixos e variáveis) nos valores dos fretes finais cobrados para a descrita movimentação da commodity até o porto. Analisada a importância do frete rodoviário na formação do preço final do açúcar para exportação, nota-se que este possui grande variabilidade devido a diversos fatores formadores do valor do frete, dentre eles, os custos de transporte.

Palavras-chave: açúcar, exportação, modal rodoviário, frete, custos de transporte.

Recebido em: 23/12/09; Aceito em: 06/04/10.

2 Graduanda em Engenharia Agronômica pela Universidade de São Paulo (ESALQ/USP). E-mail: carolina.oliveira@usp.br

3 Graduando em Engenharia Agronômica pela Universidade de São Paulo (ESALQ/USP). E-mail: coliva@esalqlog.esalq.usp.br

4 Graduanda em Ciências Econômicas pela Universidade de São Paulo (ESALQ/USP). E-mail: dani.passoni@uol.com.br

5 Graduando em Ciências Econômicas pela Universidade de São Paulo (ESALQ/USP).

E-mail: joao.loreti@usp.br

6 Graduanda em Engenharia Agronômica pela Universidade de São Paulo (ESALQ/USP). E-mail: marianastefanini@yahoo.com.br

7 Graduanda em Engenharia Agronômica pela Universidade de São Paulo (ESALQ/USP). E-mail: rreijers@esalq.usp.br

8 Professor Titular da ESALQ/USP. E-mail: jvcaixet@esalq.usp.br 


\section{Introdução}

\subsection{Produção e exportação nacional de açúcar}

O açúcar é uma commodity cuja produção mundial está distribuída entre vários países, e os principais países produtores, em ordem crescente de produção, são China, Índia e Brasil. Entretanto, grande parcela do açúcar chinês abastece sua demanda interna, e quantidades são destinadas à exportação; já o açúcar indiano tem maior participação no mercado mundial, mas o volume movimentado não é suficiente para colocá-lo no patamar de maior produtor e exportador mundial, razão pela qual o Brasil fica com essa classificação.

Na safra 2008/09, a produção brasileira representou 21,75\% do açúcar mundial, e suas exportações, aproximadamente, $42 \%$ de todo açúcar movimentado (USDA, 2009). Atualmente, o maior polo produtor açucareiro do Brasil é a região Centro-Sul, que abrange, dentre outros, o estado de São Paulo, cuja produção, na última safra, correspondeu a $62 \%$ da produção nacional. Além de maior produtor, esse estado é sede dos principais terminais exportadores de açúcar, situados no Porto de Santos.

As mesorregiões de maior destaque na produção açucareira paulista, na safra 2008/09, foram Ribeirão Preto, São José do Rio Preto, Bauru, Piracicaba e Assis. As regiões supramencionadas foram listadas com base no critério decrescente de suas respectivas participações no montante produzido de açúcar (UNICA, 2009).

A safra da cana-de-açúcar, o volume de açúcar produzido e exportado, a sazonalidade de produção, dentre outros, têm influência direta na configuração das estratégias logísticas adotadas. Ao diagnosticar o comportamento do mercado ao longo do ano, assim como a disponibilidade de veículos nas diferentes épocas, é possível prever a oferta pelo serviço de transporte e pela ordem de grandeza do valor de frete a ser praticado. 
Carolina F. Oliveira, Ciro Villela Oliva, Daniela C. Passoni, João Victor Crivellaro Loreti, Mariana Papa Stefanini, Rhuana Reijers \& José Vicente Caixeta Filho

\subsection{Situação logística atual no mercado sucroalcooleiro}

O transporte do açúcar dos centros produtores até os portos é feito, na maioria dos casos, a granel e realizado unimodalmente por rodovia. Entretanto, existem alternativas intermodais, como a integração entre rodovia e ferrovia. De maneira geral, há baixa especificidade e permanência dos veículos no mercado spot, e as operações de carga, descarga e transporte são feitas 24 horas por dia, ininterruptamente.

As vantagens do transporte rodoviário podem ser obtidas pela maior flexibilidade deste modal, além da maior agilidade, quando comparado com os demais, possibilitando, assim, um serviço de transporte a curtas distâncias, que apresente maior necessidade de distribuição "pulverizada". No entanto, apresenta baixa capacidade de carga, baixa oferta nos picos de safra e, devido aos elevados custos variáveis, tem os maiores valores de frete, comparativamente aos modais ferroviário e aquaviário.

Nos terminais portuários brasileiros, ainda se observam problemas de acesso rodoviário, visualizáveis a partir dos congestionamentos nos períodos de safra. Além disso, apresentam calado limitante às embarcações de grande porte e capacidades de armazenamento incompatíveis com a demanda do produto atingida em períodos de picos de safras, nas zonas retro portuárias e portuárias. A infraestrutura logística deficitária nacional tem se revelado como um gargalo importante no âmbito de maior desenvolvimento agroindustrial brasileiro, uma vez que ocasiona impactos relevantes no denominado "Custo Brasil" e coloca o país em posição de menor competitividade no cenário internacional, apesar do elevado potencial produtivo.

\subsection{Custos fixos e variáveis do modal rodoviário}

Cada modal apresenta seu custo de transporte, resultante da soma dos custos fixos e variáveis. O custo fixo deriva de toda despesa obtida independente do volume de venda, enquanto o variável depende diretamente da utilização do veículo e aumenta em virtude da intensidade 
de uso. Considerando que a movimentação de açúcar é feita, principalmente, pelo modal rodoviário, por meio do veículo do tipo Bitrem Basculante, serão detalhados, a seguir, os custos inerentes a esse veículo.

Os custos fixos são mensurados em $\mathrm{R} \$$ /hora e abrangem gastos com elementos que independem da utilização do veículo, como depreciação do veículo, remuneração de capital, mão-de-obra e seguro obrigatório (IPVA). Em contrapartida, os custos variáveis, mensurados em R \$/ $\mathrm{km}$, abrangem os gastos resultantes da utilização do veículo, como combustível, óleo combustível e diferencial, lubrificação, pneu, lavagem e manutenção do veículo.

Além das características intrínsecas do veículo, a distância do percurso é o fator que mais influencia no custo do transporte, já que atua nos custos variáveis. Considerando uma distância de $400 \mathrm{~km}$ a ser percorrida por um Bitrem Basculante, observa-se que a participação dos elementos que compõem o custo fixo é de $25,7 \%$ e do custo variável, de $74,3 \%$. A Figura 1 apresenta a participação de cada elemento que compõe o custo total.

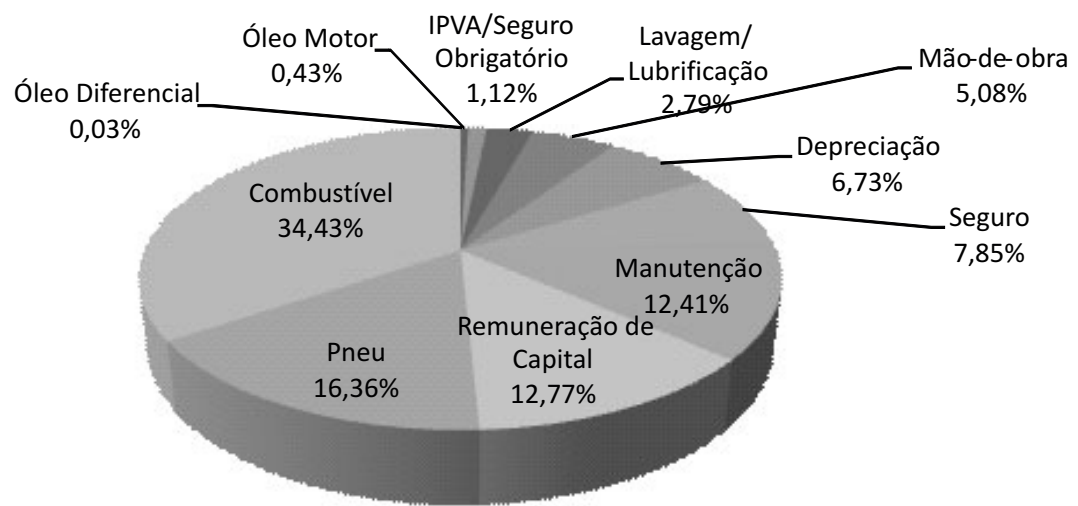

Figura 1 - Participação dos itens de custos fixos e custos variáveis no custo total de um Bitrem Graneleiro $37 \mathrm{t}$, considerando uma rota de 400 quilômetros.

Fonte: ESALQ-LOG(2009). 
Carolina F. Oliveira, Ciro Villela Oliva, Daniela C. Passoni, João Victor Crivellaro Loreti, Mariana Papa Stefanini, Rhuana Reijers \& José Vicente Caixeta Filho

Da mesma maneira que no custo do transporte, a distância é um fator primordial na precificação do frete; assim, foram utilizados alguns critérios para o estabelecimento da área de estudo, a qual permitiu o traçado de rotas representativas.

\section{Metodologia}

\subsection{Critérios de delimitação da área de estudo}

A escolha da área de estudo partiu da determinação do estado de maior representatividade na produção de açúcar, frente ao contexto nacional. A partir dessa delimitação inicial, procurou-se mapear as regiões que contribuem, significativamente, para esse Estado produtor. Nesse mapeamento, utilizou-se o critério de segmentação geográfica, adotado como parâmetro pelo Instituto Brasileiro de Geografia e Estatística (IBGE), em termos de "mesorregiões". A partir da segmentação geográfica supramencionada, foi possível aplicar a restrição da área de abrangência do estudo, visto que foram incluídas apenas as regiões que continham unidades processadoras de cana-de-açúcar.

Por meio das mesorregiões selecionadas, partiu-se para a caracterização das unidades produtoras de açúcar, adotando-se, como critérios, a capacidade de moagem das plantas industriais, assim como os montantes produzidos de açúcar na safra 2008/09. A caracterização das unidades processadoras de cana-de-açúcar permitiu correlacionar os parâmetros de produção e as respectivas localizações das plantas industriais. Nesse sentido, a partir da agregação dos dados anteriores, foram identificadas as cidades com maior produção dentro de cada mesorregião, as quais serão denominadas, no presente trabalho, de centroides de oferta de açúcar.

A oferta de açúcar das cidades das mesorregiões utilizadas no embasamento do estudo foi determinada de acordo com as respectivas produções das usinas de cana-de-açúcar, as quais foram levantadas a 
partir das bases de dados e cadastros de instituições como União da Indústria de Cana-de-Açúcar (UNICA), Ministério da Agricultura, Pecuária e Abastecimento do Governo Federal (MAPA) e Anuário da Cana (2009), e de fontes que também foram utilizadas, anteriormente, na determinação das mesorregiões com produção de açúcar. Ademais, observa-se, nos centroides, a representativa demanda de serviços de transportes decorrente da elevada oferta de cargas do setor sucroalcooleiro, fato que auxiliou na determinação pontual de tais localidades ofertantes de açúcar, para cada mesorregião, justificando, assim, a análise do comportamento dos fretes originados.

Desse modo, a partir dos centroides selecionados, procurou-se estabelecer um conjunto de matrizes origem-destino, com base no principal porto brasileiro de captação de açúcar para comercialização ao mercado externo. Nesse sentido, a definição do principal porto de captação da carga supracitada ocorreu a partir da análise de dados de exportação relativos ao ano-base de 2008, de todos os portos nacionais, provenientes do Sistema de Análise das Informações de Comércio Exterior via internet (ALICE-Web), cujo desenvolvimento e manutenção são de responsabilidade da Secretaria de Comércio Exterior (SECEX).

Com base nas delimitações dos centroides ofertantes do produto açúcar e do principal destino com relação às exportações brasileiras, obteve-se um conjunto de fluxos que serviram como base para presente estudo, devido à sua representatividade socioeconômica na área delimitada, assim como pela sua importância no setor de transportes.

\subsection{Custos de transportes}

Os valores estimados para o frete rodoviário basearam-se no custo de transporte para esse modal, calculado pelo método de custeio de transportes proposto por Lima (2005), assim definido: 
Carolina F. Oliveira, Ciro Villela Oliva, Daniela C. Passoni, João Victor Crivellaro Loreti, Mariana Papa Stefanini, Rhuana Reijers \& José Vicente Caixeta Filho

A. Custos fixos: depreciação; remuneração do capital, pessoal (motorista), custos administrativos, seguro do veículo, IPVA/ seguro obrigatório.

- Custo de depreciação: $C_{\text {dep }}=\frac{\text { Valor aquisigão-Valor residuo }}{\text { vida útil (meses) }}$.

- IPVA / Seguro: $C_{I P V A / s e g}=\frac{\text { Despesa total (anual) }}{12}$

\section{- Custos administrativos:}

$C_{\text {adm }}=\frac{\text { Custo administrativo total (mensal) }}{\text { número de veículos }}$

\section{- Custo com pessoal:}

salários + encargos e benefícios (mensal)

\section{- Custo de remuneração de capital:}

$C_{\text {rem cap }}=$ Valor aquisiçãox $(\sqrt[12]{(1+}$ juro anual $)-1$

B. Custos variáveis: pneus, combustível, lubrificantes, lavagem, lubrificação, manutenção e pedágio.

\section{- Gastos com pneu:}

$C_{\text {pneu }}=\frac{n_{\text {pneu }}^{2} x\left(p_{1}+n^{2} \text { recapagem } x p_{2}\right)}{\text { vida útil do pneu em km com recapagem }}$ em que $p_{1}$ é o preço unitário do pneu novo e $p_{2}$, preço da recapagem.

- Gastos com combustível: $C_{\text {comb }}=\frac{\text { preģo do combustivel }}{\text { rendimento }}$ 


\section{- Gastos com lavagem e lubrificação:}

$$
C_{\text {lub }}=\frac{\text { custo lubrificagão }}{\text { distancia percorrida entre intervalos }}
$$

\section{- Gastos com manutenção:}

$C_{\operatorname{man}}=$ custo de manutenção por $\mathrm{km}$ rodado.

Com base no modelo apresentado para o custeio do transporte rodoviário e nos respectivos parâmetros coletados pelo Grupo de Pesquisa e Extensão em Logística Agroindustrial (ESALQ-LOG), os custos fixos foram convertidos em coeficiente de custo fixo (CF), em $\mathrm{R} \$ / \mathrm{h}$, e os custos variáveis, em coeficiente de custo variável $(\mathrm{CV})$, em $\mathrm{R} \$ / \mathrm{km}$.

Os parâmetros que alimentaram o modelo de custos correspondem aos valores de mercado dos insumos, ao longo dos meses do ano de 2008, para o veículo do tipo Bitrem Graneleiro, com capacidade para 37 toneladas de carga líquida. Além disso, considerou-se a velocidade média de percurso igual a $60 \mathrm{~km} / \mathrm{h}$ e $0,5 \mathrm{~h}$ para cada operação de carga ou descarga do veículo.

A estimativa das distâncias entre origem e destino das rotas analisadas baseou-se em dados obtidos do software do Guia Quatro Rodas, versão 2009. Nesse sentido, foram usados, como critérios para roteirização, os percursos mais rápidos, visto que estes geralmente correspondem aos trajetos nas melhores rodovias, o que possibilita estimar o tempo de viagem. Por fim, o custo do frete estimado para cada rota foi calculado a partir das seguintes equações: 
Carolina F. Oliveira, Ciro Villela Oliva, Daniela C. Passoni, João Victor Crivellaro Loreti, Mariana Papa Stefanini, Rhuana Reijers \& José Vicente Caixeta Filho

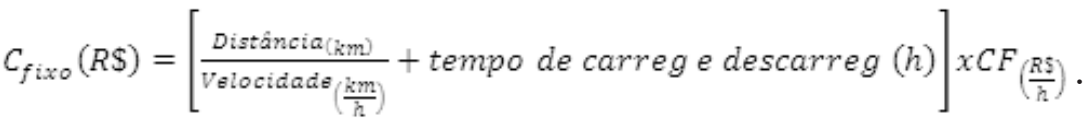

$$
\begin{aligned}
& C_{\text {variável }}(R \$)=\operatorname{Distância~}_{(\mathrm{km})} x C V_{\left(\frac{R \Im}{h k m}\right)} . \\
& \text { Preço viagem }_{t}\left(\frac{R S}{t}\right)=\frac{\text { Custo }_{\text {Fixo }}(R S)+{\text { Custo } \text { Variável }_{(R S)}}_{\text {capacidade de carga liquida }(t)}}{\text {. }}
\end{aligned}
$$

Obteve-se, assim, o custo de transporte rodoviário correspondente a cada rota proposta para análise. Com vistas em comparar esses custos com os valores de fretes praticados na exportação de açúcar nas rotas selecionadas para o estudo, usou-se o banco de dados primários do Grupo ESALQ-LOG (2008), composto por valores de fretes rodoviários, contratados pelo agente empresa, com pedágio e sem ICMS, mensurados em reais por tonelada $(\mathrm{R} \$ / \mathrm{t})$ de açúcar.

\section{Resultados}

Dado o contexto supracitado, as matrizes origem-destino de açúcar analisadas no presente trabalho compreendem os centroides de maior produção e o porto de maior movimentação. Ao proceder-se à determinação dos centroides, selecionaram-se as principais mesorregiões produtoras de açúcar, seguindo o critério de produção de açúcar, segundo dados da UNICA (2009). Nas mesorregiões estão inseridos os centroides produtores, que são os mais representativos em volume de açúcar produzido, selecionados para a análise proposta.

Definidas as origens, adotou-se como destino o Porto de Santos, o qual foi responsável pala exportação do peso líquido de 8.712.821 toneladas de açúcar, no período de janeiro a dezembro de 2008, correspondendo a $64 \%$ das exportações da commodity pelo Brasil, no período. A Figura 2 
ilustra a posição espacial das origens e do destino, adotada na análise proposta.

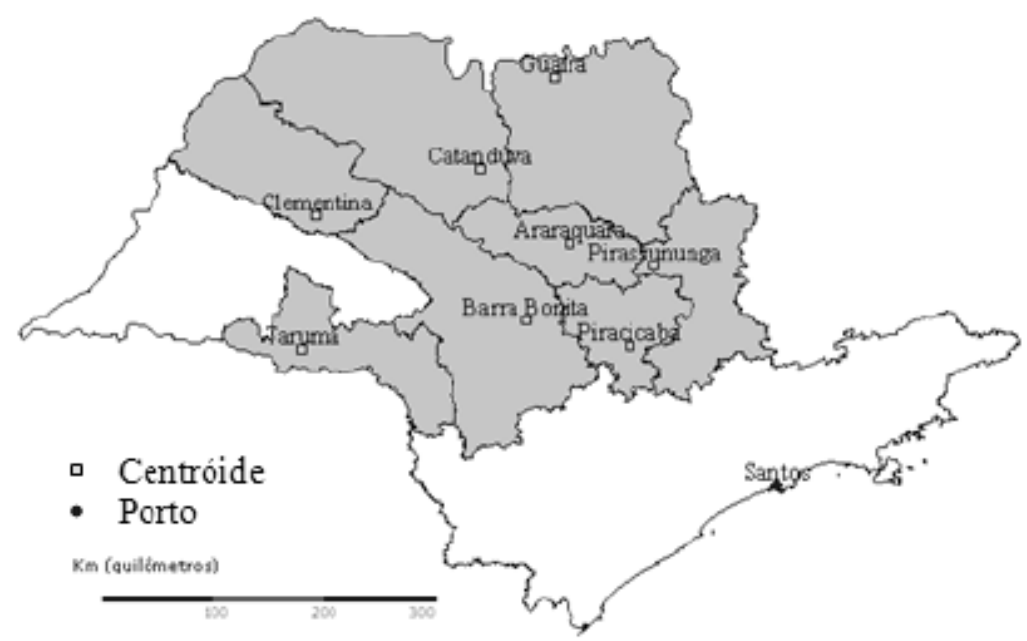

Figura 2 - Mapa representativo dos centroides ofertantes de carga e do porto de destino do açúcar analisados pelo estudo.

Fonte: Elaborado pelos autores, por meio do Software GISMAPS VIEWER.

Após a determinação das matrizes origem-destino, obtiveram-se os preços do serviço de transporte, praticado ao longo do ano de 2008, na exportação de açúcar, a fim de analisar o comportamento do setor em frente às variáveis que impactam a formação do preço do frete. Esses valores são definidos a partir dos custos de transporte somados aos fatores de mercado. 
Carolina F. Oliveira, Ciro Villela Oliva, Daniela C. Passoni, João Victor Crivellaro Loreti, Mariana Papa Stefanini, Rhuana Reijers \& José Vicente Caixeta Filho

\subsection{Dimensão da diferença entre o valor de frete e o custo de transporte}

Tendo em vista o escopo do trabalho, a junção das informações, coletadas pelo Grupo ESALQ-LOG (2008), permitiu a realização de uma análise minuciosa das variáveis componentes do custo fixo e variável e do frete de açúcar destinado à exportação, cuja representação consta nas Figuras $3,4,5,6,7,8,9$ e 10 .
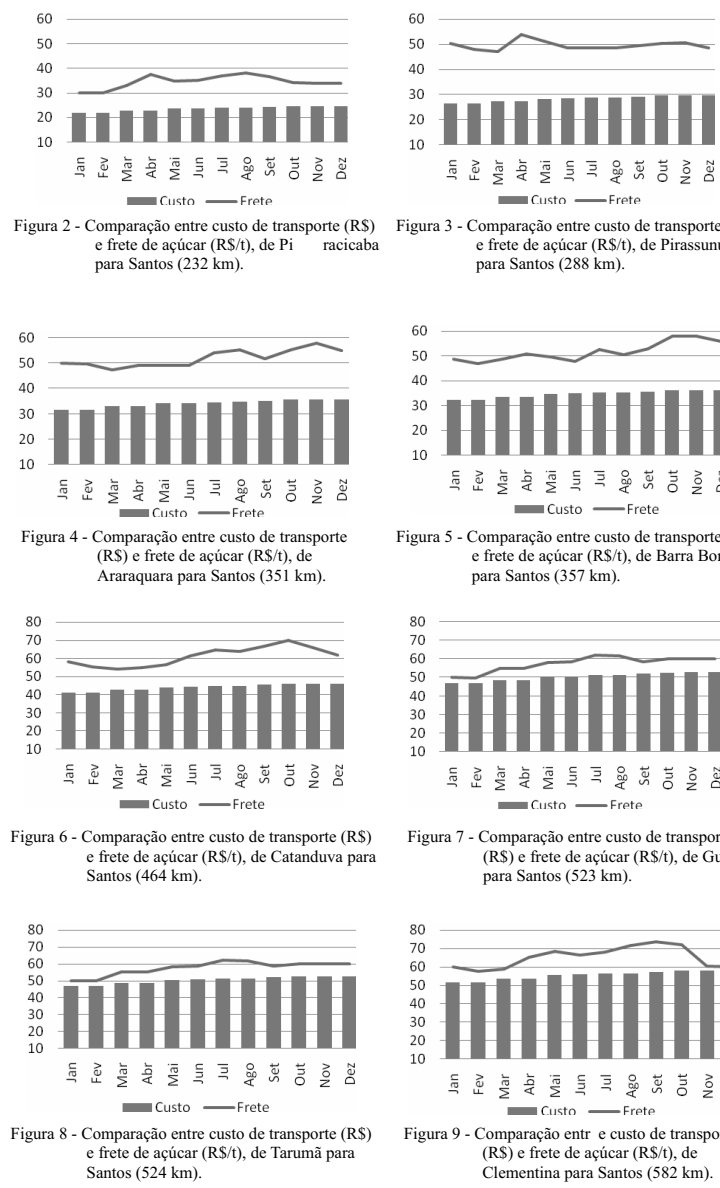

mparação entre custo de transporte (R\$) e frete de açúcar $(\mathrm{R} \$ \mathrm{t})$, de Pirassununga para Santos $(288 \mathrm{~km})$

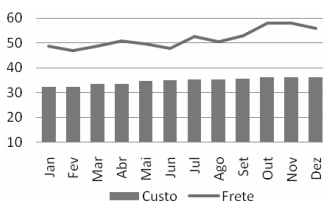

Figura 5 - Comparação entre custo de transporte $(\mathrm{R} \$)$
e frete de açúcar $(\mathrm{R} \$ / \mathrm{t})$, de Barra Bonita para Santos $(357 \mathrm{~km})$
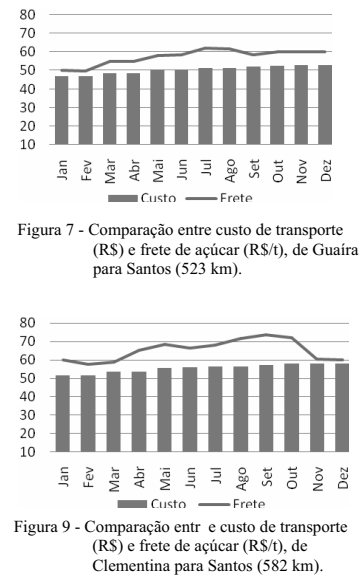


\subsubsection{Variação dos componentes do custo fixo e variável}

No primeiro trimestre de 2008 , foram constatadas alterações significativas nos principais itens que compõem os custos fixo e variável e que influenciam, diretamente, o valor final do custo total, como cavalo, reboque e óleo para diferencial, com aumentos de $12,15 \%, 12,05 \%$ e $6,79 \%$, respectivamente. Já no segundo trimestre do ano, os itens que se destacaram foram o salário, devido ao reajuste do salário mínimo de, aproximadamente, $9 \%$, sendo que esta alteração positiva foi repassada, gradativamente, para os motoristas; e devido à alta nos combustíveis, dada a elevação do barril do petróleo no mercado internacional, o que fez com que esse componente sofresse alta de 9,62\%. Em contrapartida, a redução nos preços do pneu, devido à queima de estoque realizada pelas lojas do setor, resultou em redução equivalente a 4,92\%.

No terceiro trimestre, foi possível observar grande ajuste no preço do reboque, em cerca de $10,48 \%$, decorrente da elevação do preço do aço no mercado internacional, o que refletiu, diretamente, neste componente. Vale ressaltar a contínua elevação dos derivados de petróleo, como o óleo para o diferencial e para o motor, com ajustes respectivos de 4,5\% e 3,5\%, cujos valores também foram reajustados, no quarto trimestre, em $12,7 \%$ e $13,5 \%$. A recapagem dos pneus também passou por reajustes consecutivos de $7,68 \%$, no terceiro trimestre, e de $11,8 \%$, no quarto.

As alterações verificadas ao longo do ano de 2008 estão sumarizadas na Tabela 1. 
Carolina F. Oliveira, Ciro Villela Oliva, Daniela C. Passoni, João Victor Crivellaro Loreti, Mariana Papa Stefanini, Rhuana Reijers \& José Vicente Caixeta Filho

Tabela 1 - Variação percentual nos valores dos componentes do custo fixo e custo variável, durante o ano de 2008

\begin{tabular}{lcccc}
\hline & $\mathbf{1}^{\circ}$ Trimestre & $\mathbf{2}^{\circ}$ Trimestre & $\mathbf{3}^{\circ}$ Trimestre & $\mathbf{4}^{\circ}$ Trimestre \\
\hline Salário & - & $4,40 \%$ & - & - \\
Cavalo & $12,15 \%$ & $3,82 \%$ & $2,31 \%$ & $-0,50 \%$ \\
Reboque & $12,05 \%$ & $3,90 \%$ & $10,48 \%$ & $1,00 \%$ \\
Óleo Motor & $2,41 \%$ & $4,03 \%$ & $4,50 \%$ & $12,70 \%$ \\
Óleo Diferencial & $6,79 \%$ & $4,54 \%$ & $3,50 \%$ & $13,50 \%$ \\
Combustível & $1,00 \%$ & $9,62 \%$ & $0,40 \%$ & $0,10 \%$ \\
Pneu & $1,60 \%$ & $-4,92 \%$ & $-0,23 \%$ & $11,80 \%$ \\
Recapagem & $3,40 \%$ & $0,60 \%$ & $7,68 \%$ & $1,10 \%$ \\
Lavagem/ & - & - & - & - \\
Lubrificação & - & & & \\
\hline
\end{tabular}

Fonte: Grupo ESALQ-LOG (2009).

Com base nos gráficos relativos aos fretes comparados aos custos, observa-se, de maneira geral, nos centroides estudados uma constância nos valores de custos, como era previsto, apenas com tendência mínima de aumento no decorrer dos meses e aproximação do final do ano, como já tratado anteriormente.

\subsubsection{Análise da variação dos valores de frete de açúcar exportação}

Além do custo, têm-se as variáveis de mercado, que compõem a parcela dinâmica do comportamento do frete. Durante o ano, verifica-se sazonalidade nos preços do frete, resultado de diversos fatores como a relação entre oferta e demanda de carga e de veículos disponíveis para o transporte; política comercial das empresas transportadoras; fatores climáticos sobre a cultura de cana-de-açúcar e sobre as condições para as operações logísticas; preço do Real frente ao Dólar, bem como preço do produto no mercado internacional; custos logísticos, envolvendo 
armazenamento e transporte; transit-time; e eficiência portuária de descarregamento.

Ao agregar as informações de custo de transporte e variações mercadológicas, por meio do acompanhamento realizado pelo Grupo ESALQ-LOG (2008), notou-se um comportamento semelhante entre os fluxos estabelecidos a partir dos centroides e o Porto de Santos no período de entressafra, correspondente à época que antecede as operações de colheita da safra vigente. O intervalo relativo aos meses de janeiro a meados de março representa o momento de pouca oferta de açúcar, com ligeira movimentação de produto de safras anteriores estocados, o que contrasta com a elevada oferta de veículos disponíveis para o transporte. Esse cenário, de maneira geral, manteve os fretes em patamares baixos e em algumas regiões, como Pirassununga, Araraquara, Barra Bonita, Tarumã e Clementina, houve sensível queda nos valores de frete. Aliado a esses fatores, a baixa demanda internacional revelouse essencial para a reduzida movimentação.

A segunda quinzena de março foi marcada pelo início da safra na maioria dos centroides, o que aumentou a oferta de produto no mercado e a consequente demanda do transporte rodoviário. Entretanto, houve deslocamento da frota de veículos nesse período para o Centro-Oeste do país, dado o início da safra de soja, que oferece maiores volumes de carga e melhor remuneração pelo serviço de transporte, em comparação ao açúcar paulista. Tal fato resultou no aumento dos valores de frete em todos os centroides, exceto em Araraquara e Catanduva, que apresentaram redução no valor do frete, visto que suas colheitas de canade-açúcar começavam apenas em meados abril, razão pela qual não refletiam na variação positiva do frete.

Já no mês de abril, notou-se aumento generalizado dos valores cotados para as atividades de transporte, com exceção de Tarumã, que apresentou estabilidade no preço do frete em relação ao mês de março, além de diferentes comportamentos mercadológicos terem sido verificados. Os centroides, como Piracicaba, Barra Bonita e Pirassununga, apresentaram 
Carolina F. Oliveira, Ciro Villela Oliva, Daniela C. Passoni, João Victor Crivellaro Loreti, Mariana Papa Stefanini, Rhuana Reijers \& José Vicente Caixeta Filho

redução nos fretes em maio, devido ao menor volume de açúcar escoado para o mercado externo. Em contrapartida, os demais centroides mantiveram a tendência crescente nos valores de frete, justificada pelo gradativo aumento da oferta de açúcar, o que contrastou com a excedente oferta de soja nos Estados do Centro-Oeste, produtos concorrentes pelo serviço de transporte.

Os centroides de Barra Bonita, Piracicaba e Pirassununga apresentaram intensa redução do frete no mês de maio, ante o mês de abril, tendência que se manteve no mês de junho para Pirassununga e Barra Bonita, bem como para Clementina. Essas reduções foram decorrentes da baixa atratividade na exportação de açúcar, visto que o preço da saca no mercado internacional seguia tendência de decréscimo que perdurou até julho. O centroide de Araraquara mostrou-se estável entre os meses de abril a junho, ao passo que Guaíra, Catanduva e Tarumã apresentaram aumentos mais expressivos nesse período. Em Catanduva, o modal ferroviário apresentou-se como substituto do modal rodoviário, em razão da necessidade do direcionamento de lotes de açúcar para o Porto de Santos, contraposta à baixa oferta de caminhões. Já Tarumã registrou ações grevistas desencadeadas por agentes do transporte rodoviário, no referido período, o que suspendeu os embarques de açúcar.

Apesar de o menor preço da saca de açúcar ter sido registrado no mês de julho, esse é o período que corresponde ao início do pico de movimentação em praticamente todos os centroides considerados no estudo. No setor de transportes, esse fato tendeu a incorrer em elevações nos valores de fretes, as quais são decorrentes da menor oferta de veículos para a movimentação do açúcar durante a safra. Esse cenário de reduzido valor do produto e de elevação do preço do frete é típico do período de safra, quando a oferta de produto no mercado e a demanda do serviço de transporte aumentam.

Tal aumento tendeu a manter a oferta de serviço do setor supramencionado no local, bem como sugeriu o deslocamento de veículos atuantes em outras regiões do país. Associados a este cenário estão o 
aumento do preço do óleo diesel e a adoção da política de limitação de horário para transitar na cidade de São Paulo - o que restringe a flexibilidade característica do modal rodoviário.

Em todos os centroides, os fatores supracitados foram variáveis significativas para explicar a elevação dos preços do frete ao longo do mês de julho. No que se diz respeito ao volume de açúcar direcionado ao Porto de Santos, notam-se, em Araraquara, constantes reduções, o que contrapõe a tendência de safra observada nas demais regiões. Ao longo do mês de agosto, observaram-se aumentos nos valores de frete em Clementina, Barra Bonita, Piracicaba e Araraquara, decorrentes do não balanceamento entre oferta de veículos e demanda do serviço de transporte. As demais regiões ficaram estáveis, em relação ao mês de julho.

O mês de setembro foi marcado por diferentes cenários, já que houve divergências nas estratégias comerciais adotadas pelas usinas, tais como a formação de estoque ou a comercialização. A primeira estratégia foi implantada nos centroides de Tarumã, Piracicaba e Araraquara, cujo reflexo no frete foi sua ligeira redução. Outras regiões apresentaram aumento no frete, em virtude da maior oferta de açúcar contraposta à concorrência dos veículos com os grãos de segunda safra do CentroOeste do país. Já no mês de outubro, todas as regiões apresentaram queda nos valores de frete, ante à tendência de formação de estoques resultante da baixa atratividade em exportar açúcar no referido mês. Entretanto, os centroides de Pirassununga, Barra Bonita, Catanduva e Guaíra registraram elevação em suas cotações, dado o deslocamento dos veículos para regiões ofertantes de cargas, tais como Mato Grosso, Goiás e Paraná.

A conjuntura macroeconômica da crise financeira mundial favoreceu a prática de formação de estoque já evidenciada nos meses anteriores, devido à instabilidade nas negociações comerciais com grandes compradores internacionais. Aliado a isso, o término do período de safra contribuiu para a tendência de redução dos valores praticados no mercado de frete a partir do mês de novembro. 
Carolina F. Oliveira, Ciro Villela Oliva, Daniela C. Passoni, João Victor Crivellaro Loreti, Mariana Papa Stefanini, Rhuana Reijers \& José Vicente Caixeta Filho

\section{Conclusões}

Com base nos gráficos comparativos de cada centróide, referentes aos fretes e aos custos destinados a Santos, observa-se, de maneira geral, constância nos valores de custos com o decorrer dos meses de 2008, apenas com tendência mínima de aumento com o passar dos meses, sendo os valores dos custos de novembro e dezembro os mais elevados do ano. Tal fato se explica pela tendência de compra de novas carretas no início do ano; assim, normalmente nos últimos meses, a depreciação e os custos fixos dos veículos de transporte tenderam a ser ligeiramente mais altos que nos demais meses do ano, que compreende um ciclo de janeiro a dezembro.

Ao analisar, de maneira geral, os custos variáveis, observa-se estabilidade na maioria dos produtos que os compunham durante os meses de 2008, salvo algumas ocasiões como as relacionadas com alta do petróleo e alta da borracha (e em consequência do pneu); em todos os casos, esses aumentos não foram repassados imediatamente para os preços de mercado, mas de forma gradativa ao longo do ano. Desse modo, dificilmente, fatos pontuais que elevam ou decrescem os custos fixos e variáveis de transporte são repassados em valores para o frete final cobrado dos embarcadores. Apenas um fato extremo faria com que os custos variassem drasticamente; como consequência, os fretes acompanhariam tal tendência, caso não ocorrido no período estudado.

Em relação aos fretes praticados nas rotas estudadas de açúcar de exportação para o Porto de Santos, comparados com os custos, de que trata o objetivo da pesquisa, a diferença observada ficou em torno de $40 \%$, uma vez que o frete-empresa, teoricamente, continha embutido em seu valor o custo relativo ao transporte, permanecendo, assim, em um patamar elevado em todos os meses; porém, em se tratando de uma commodity agrícola, com o decorrer do ano de 2008, peculiaridades discutidas anteriormente fizeram com que esses fretes variassem de maneira mais significativa, em razão de diversos fatores, como época do ano, queda ou saída de safra, crise financeira mundial, entre outros. Nesse 
sentido, observa-se no centroide Pirassununga a origem de maior discrepância entre os fretes praticados e os custos, com diferença de $75 \%$, visto que tal situação se explica pela existência de pedágios em meio à rota destinada a Santos. Já no caso de Tarumã, nota-se menor diferença entre os centroides estudados, a qual ficou em torno de $14 \%$, uma vez que as mais longas rotas estudadas apresentavam menores amplitudes entre frete e custo.

Assim, essa oscilação e a sazonalidade dos valores dos fretes não foram acompanhadas por uma variação similar por parte dos custos de transporte, de modo que a diferença entre os dois fatores também ilustrou a margem de lucro praticada por empresas do transporte rodoviário. Portanto, salvo alguma alteração muito drástica e direta nos custos fixos ou variáveis de transporte, estes observam um referencial de valor bastante comportado; já os picos e sazonalidades dos fretes, por várias razões, causam modificações diretas nos valores dos fretes, o que interfere no mercado em valores reais e mais elásticos que os custos de transporte.

Em se tratando da comparação dos valores referentes aos custos de transporte no decorrer do ano, as rotas dos centroides até o porto apresentaram valores médios distintos, pois os custos variáveis foram calculados também em decorrência da distância de cada rota, devido, principalmente, ao consumo de combustível e de pneus. Assim, os centroides mais distantes do Porto de Santos apresentaram, em média, custos finais maiores do que os mais próximos, diferentemente do chamado "momento de frete" (R $\$ / \mathrm{t} . \mathrm{km})$, que tratava de uma grandeza com valor diretamente proporcional em relação à distância percorrida. 
Carolina F. Oliveira, Ciro Villela Oliva, Daniela C. Passoni, João Victor Crivellaro Loreti, Mariana Papa Stefanini, Rhuana Reijers \& José Vicente Caixeta Filho

\section{Referências}

ADMINISTRAÇÃO DOS PORTOS DE PARANAGUÁ E ANTONINA - APPA. Estatísticas mensais de exportação de açúcar, 2009. Disponível em: http://www.appa.pr.gov.br/modules/conteudo/ conteudo.php?conteudo=63. Acesso em set. 2009 .

BOWERSOX, D. J.; CLOSS, D. J. Logística empresarial: o processo de integração da cadeia de suprimento. São Paulo: Atlas, 2001. 549p.

BOWERSON, D. J.; COOPER, M. B.; CLOSS D. J. Gestão Logística de Cadeias de Suprimentos. São Paulo: Editora Bookman, 2006. P. 294-296.

BRASIL. SECRETARIA DO COMÉRCIO EXTERIOR - SECEX. Sistema de análise das informações de comércio exterior ALICEWeb. Disponível em: http://aliceweb.desenvolvimento.gov.br. Acesso em: ago. 2009.

CAIXETA FILHO, J. V.; GAMEIRO, A. H. (Org.). Transporte e Logística em Sistemas Agroindustriais. São Paulo: Atlas, 2001. 218p.

EDITORA ABRIL. Guia Quatro Rodas 2007. São Paulo, 2007.1 CDROM.

GISMAPS SISTEMAS. Gismaps Viewer, 2009. 1 CD-ROM.

GRUPO DE PESQUISA E EXTENSÃO EM LOGÍSTICA AGROINDUSTRIAL (ESALQ-LOG). Disponível em: http:// log.esalq.usp.br. Acesso em: set. 2009.

HIJJAR, M. F. Avaliação do Acesso aos Terminais Portuários e Ferroviários de Contêineres no Brasil. Revista Tecnologística, São Paulo, v.12, n. 130, p. 62 - 68, set. 2006. 
LIMA, M. P. O Custeio do Transporte Rodoviário. 2005. Disponível em: www.coppead.com.br. Acesso em: set. 2009.

NAZÁRIO, P.; FLEURY P. F.; WANKE, P. O papel do transporte na estratégia logística, 2000. Disponível em: http://www.ilos.com.br/site/ index.php?option $=$ com content $\&$ task $=v i e w \& i d=1107 \&$ Itemid $=182$. Acesso em: set. 2009.

OLIVEIRA, A. M. K. Potencial da logística ferroviária para a movimentação de açúcar para a exportação no estado de São Paulo. Dissertação (Mestrado em Economia Aplicada) - Universidade de São Paulo, Piracicaba, 2005.

PACHECO, E. A; DROHOMERETSKI, E.; CARDOSO, P. A. A Decisão do Modal de Transporte através da Metodologia AHP na Aplicação da Logística Enxuta. 2008. Trabalho apresentado ao $5^{\circ}$ Congresso Nacional de Excelência em Gestão, Rio de Janeiro. P. 5 - 6.

PEREIRA, F. S. Logística no Interior de São Paulo. Impacto da Densidade das Mercadorias. 2009. Disponível em: http:// loginteriorsp.blogspot.com/2009/06/impacto-da-densidade-dasmercadorias.html. Acesso em: set. 2009.

PORTO DE SANTOS. Estatísticas mensais de exportação de açúcar, 2008. Disponível em: http://www.portodesantos.com.br/down/ analise/AMF-2009-07.pdf. Acesso em: set. 2009.

SISTEMA DE INFORMAÇÕES DE FRETES PARA CARGAS AGRÍCOLAS (Sifreca). Disponível em: $\underline{\text { http:// }}$ sifreca.esalq.usp.br.Acesso em: set. 2009

UNIÃO DA AGROINDÚSTRIA CANAVIEIRA DE SÃO PAULO UNICA. Produção de açúcar do Brasil. Disponível em: http:// www.unica.com.br/dadosCotacao/estatistica. Acesso em: set. 2009.

UNIÃO DA AGROINDÚSTRIA CANAVIEIRA DE SÃO PAULO - 
Carolina F. Oliveira, Ciro Villela Oliva, Daniela C. Passoni, João Victor Crivellaro Loreti, Mariana Papa Stefanini, Rhuana Reijers \& José Vicente Caixeta Filho

UNICA. Ranking da produção de cana, açúcar e etanol das unidades da Região Centro-Sul. Disponível em: http:// www.unica.com.br/dadosCotacao/estatistica. Acesso em: set. 2009.

UNITED STATES DEPARTAMENT OF AGRICULTURE - USDA. Sugar: world production, supply and distribution. 2008. Disponível em: http://www.fas.usda.gov/htp/sugar/2009/May\%20sugar\%202009.pdf. Acesso em: set. 2009.

\begin{abstract}
Brazil is, today, the largest producer and exporter of sugar in the world, having as main competitors and price makers India and China. In the production of this commodity, there are the sugar mills and ethanol in the State of Sao Paulo. The disposal of the product is mainly done by road transportation due to the greater speed and flexibility when compared to other modes, covering distances from production plants to their ultimate destination, the Port of Santos. In this scenario, the study evaluated the impact of transport costs (fixed and variable costs) on the values of the freight charged for the final transfer of the described commodity at the port. Analyzed the importance of the road freight for the formation of the final price of the sugar for exportation, it can be noticed that it observed great variability due to several factors, among them the cost of transportation.
\end{abstract}

Keywords: sugar exportation, road transportation, transport costs. 
REVISTA DE ECONOMIA E AGRONEGÓCIO, VOL.8, $N^{\circ} 1$ 